\title{
The Nitrated Fatty Acid 10-Nitro-oleate Diminishes Severity of LPS-Induced Acute Lung Injury in Mice
}

\author{
Aravind T. Reddy, Sowmya P. Lakshmi, and Raju C. Reddy \\ Department of Medicine, Division of Pulmonary, Allergy and Critical Care Medicine, \\ Emory University and Atlanta VA Medical Center, Atlanta, GA 30033, USA \\ Correspondence should be addressed to Raju C. Reddy, raju.reddy@emory.edu
}

Received 24 February 2012; Accepted 21 April 2012

Academic Editor: Jesse Roman

Copyright ( 12012 Aravind T. Reddy et al. This is an open access article distributed under the Creative Commons Attribution License, which permits unrestricted use, distribution, and reproduction in any medium, provided the original work is properly cited.

Acute lung injury (ALI) is an inflammatory condition culminating in respiratory failure. There is currently no effective pharmacological treatment. Nitrated fatty acids (NFAs) have been shown to exert anti-inflammatory effects. We therefore hypothesized that delivery of NFAs directly to the site of inflammation would reduce the severity of ALI. Pulmonary delivery of 10-nitro-oleate following endotoxin-induced ALI in mice reduced markers of lung inflammation and injury, including capillary leakage, lung edema, infiltration of neutrophils into the lung, and oxidant stress, as well as plasma levels of proinflammatory cytokines. Nitro-oleate delivery likewise downregulated expression of proinflammatory genes by alveolar macrophages, key cells in regulation of lung inflammation. These effects may be accounted for by the observed increases in the activity of PPAR- $\gamma$ and the PPAR- $\gamma$-induced antioxidant transcription factor Nrf2, together with the decreased activity of NF- $\kappa \mathrm{B}$. Our results demonstrate that pulmonary delivery of NFAs reduces severity of acute lung injury and suggest potential utility of these molecules in other inflammatory lung diseases.

\section{Introduction}

A variety of pulmonary and extrapulmonary insults can result in acute lung injury (ALI), which is characterized by capillary leakage and resulting pulmonary edema and hypoxemia [1]. These multiple origins of ALI are reflected in different animal models of the disease, of which pulmonary administration of bacterial endotoxin (lipopolysaccharide; LPS) is among the most common. Regardless of the precipitating cause, the earliest phases of ALI feature severe neutrophil-rich alveolar inflammation [2] and associated oxidant stress [3] that represent the proximate causes of much or all of the subsequent pulmonary injury. ALI morbidity and mortality remain high and there is no effective pharmacotherapy [4], underlining the urgent need for improved treatment modalities.

Peroxisome proliferator-activated receptor $\gamma$ (PPAR- $\gamma$ ) plays a central role in many of the feedback loops that normally limit inflammation and lead to its resolution [5-9] and is therefore a promising target for ALI pharmacotherapy.
Among the many anti-inflammatory effects attributable to PPAR- $\gamma$ activation are diminished increases in reactive oxygen species, cytokines, chemokines, and adhesion molecules [10]. A major mechanism underlying these actions is decreased activity of proinflammatory transcription factors such as NF- $\kappa$ B, AP-1, and STAT $[5,6]$. Synthetic PPAR$\gamma$ agonists are widely used for treatment of diabetes but have been associated with adverse effects. A wide variety of endogenous molecules are known to activate PPAR$\gamma$, but most either exhibit low potency or are present at low concentrations, leading to uncertainty regarding their physiological role.

Nitrated fatty acids (NFAs) are activating ligands for all three PPARs, exhibiting their greatest potency as PPAR- $\gamma$ agonists $[11,12]$. They have also been shown to exhibit a number of PPAR- $\gamma$-dependent effects, including induction of adipogenesis [11] and of CD36 receptor expression by macrophages [12]. NFAs are produced endogenously by nonenzymatic reaction of $\mathrm{NO}$ or its inorganic reaction products with naturally present unsaturated fatty acids 
[13], with positional isomers of nitro-oleic acid (OA$\left.\mathrm{NO}_{2}\right)$ and nitrolinoleic acid $\left(\mathrm{LNO}_{2}\right)$ found at the highest concentrations in human plasma $[11,14]$. The suggested PPAR- $\gamma$-mediated anti-inflammatory effects of NFAs have been supported by in vitro studies $[15,16]$, but in vivo and potentially translational studies of such effects have been limited. These considerations led us to investigate the ability of treatment with $\mathrm{OA}-\mathrm{NO}_{2}$, the most potent PPAR- $\gamma$ activating NFA [11], to reduce the severity of inflammation and lung injury in a murine model of ALI induced by LPS. In order to maximize pulmonary availability, $\mathrm{OA}-\mathrm{NO}_{2}$ was delivered directly to the lung via the intratracheal route.

\section{Materials and Methods}

2.1. Animals. Male C57BL/6 mice were obtained from Jackson Laboratories (Bar Harbor, ME) and were used at 6-8 weeks of age (20-25 g). All studies were performed according to protocols reviewed and approved by the Atlanta Veterans Affairs Medical Center Institutional Animal Care and Use Committee.

2.2. $\mathrm{OA}-\mathrm{NO}_{2}$ and LPS Administration. Mice were anesthetized with $90 \mathrm{mg} / \mathrm{kg}$ ketamine and $10 \mathrm{mg} / \mathrm{kg}$ xylazine, administered via intraperitoneal injection, and a tracheotomy was performed. ALI was then induced by intratracheal (i.t.) injection of $50 \mu \mathrm{g}$ of endotoxin (LPS) prepared from Escherichia coli O111:B6 (Sigma-Aldrich, St. Louis, $\mathrm{MO})$. Thirty min later mice were injected i.t. with $50 \mu \mathrm{g} \mathrm{OA}-$ $\mathrm{NO}_{2}$ (Cayman Chemical, Ann Arbor, MI) in $50 \mu \mathrm{L}$ of $10 \%$ DMSO or with vehicle. After a further $5.5 \mathrm{~h}$ the mice were euthanized, plasma was obtained, and lung and BAL fluid samples were collected. Neutrophil infiltration into the lung peaks approximately $6 \mathrm{~h}$ after i.t. LPS administration [17].

2.3. Lung Wet:Dry Weight Ratio. As an index of lung edema, the amount of extravascular lung water was calculated. The lower lobe of the right lung was ligated and excised and the wet weight was recorded. The lung was then placed in an incubator at $60^{\circ} \mathrm{C}$ for $24 \mathrm{~h}$ to obtain the dry weight. The wet:dry ratio was calculated by dividing the wet weight by the dry weight.

2.4. Bronchoalveolar Lavage (BAL) Fluid Collection and Cell Count. Following removal of the lung's lower right lobe, BAL fluid was collected by flushing $3 \times 1 \mathrm{~mL}$ of phosphatebuffered saline (PBS) containing $0.1 \mathrm{mM}$ EDTA into the lung via a tracheal cannula. The pooled BAL fluid was centrifuged at $500 \times g$ at $4^{\circ} \mathrm{C}$ for $5 \mathrm{~min}$. Pelleted cells were then resuspended in $1 \mathrm{~mL}$ of PBS. Total cell number was counted by hemocytometer and a differential cell count was performed by cytospin staining with Diff-Quik (Siemens, Newark, DE).

2.5. BAL Fluid Protein. Increase in BAL fluid protein concentration was taken as a measure of increased permeability of alveolar-capillary barriers. Total protein concentration in the supernatant following BAL fluid centrifugation was determined using the BCA Protein Assay kit (Pierce, Rockford, IL).

2.6. Lung Histopathology. The lungs were inflated and fixed with $10 \%$ neutral formalin overnight at room temperature. Lung tissue was dehydrated with increasing ethanol $(\mathrm{EtOH})$ concentrations and then embedded in paraffin. Five-micrometer-thick paraffin sections were stained with hematoxylin and eosin ( $\mathrm{H} \& \mathrm{E})$.

2.7. Assessment of Capillary Leakage. To further assess lung permeability, $50 \mathrm{mg} / \mathrm{kg}$ of Evans Blue Dye (EBD; SigmaAldrich, St. Louis, MO) dissolved in $200 \mu \mathrm{L}$ of PBS was injected into the tail veins of mice following ALI induction. After $30 \mathrm{~min}$, the animals were euthanized and the lungs perfused with $5 \mathrm{~mL}$ PBS, after which the lungs were excised en bloc and snap-frozen in liquid nitrogen. The frozen lungs were then homogenized in $2 \mathrm{~mL}$ PBS. The homogenate was diluted with $2 \mathrm{vol}$ of formamide and incubated at $60^{\circ} \mathrm{C}$ for $18 \mathrm{~h}$, followed by centrifugation at $5,000 \times g$ for $30 \mathrm{~min}$. The supernatant was collected and absorbance was measured at 620 and $740 \mathrm{~nm}$. The EBD concentration was determined from standard absorbance curves evaluated in parallel. Correction for contaminating heme pigments was calculated by the formula $\mathrm{E}_{620}(\mathrm{EBD})=\mathrm{E}_{620}-\left(1.426 \times \mathrm{E}_{740}+\right.$ $0.030)$. The EBD concentration was expressed as $\mu \mathrm{g}$ per $\mathrm{g}$ of lung.

2.8. Measurement of Myeloperoxidase Activity. As an index of neutrophil infiltration, BAL fluid and tissue-associated myeloperoxidase (MPO) activity was determined. Frozen lung tissues were thawed, weighed, homogenized, and sonicated on ice in radioimmunoprecipitation assay buffer (RIPA). After centrifugation at $10,000 \times g$ at $4^{\circ} \mathrm{C}$ for $20 \mathrm{~min}$, the supernatant was collected and used for determination of MPO activity by a commercially available fluorometric assay kit (700160; Cayman Chemical) according to the manufacturer's instructions. Results were expressed as nmol/minml. Similar measurements were performed on BAL fluid supernatant.

2.9. Measurement of Oxidant Stress. Hydrogen peroxide $\left(\mathrm{H}_{2} \mathrm{O}_{2}\right)$ production in lung tissue was determined using the Amplex Red Hydrogen Peroxide Assay kit (Molecular Probes, Eugene, OR) according to the manufacturer's directions. The concentrations of nitrate and malondialdehyde (MDA) in lung homogenates were measured using commercially available colorimetric assay kits (Cayman Chemical) according to the manufacturer's instructions.

2.10. Measurement of Plasma Cytokine Levels. Plasma levels of tumor necrosis factor- $\alpha$ (TNF- $\alpha$ ), interleukin-6 (IL-6), keratinocyte chemoattractant (KC), and macrophage inflammatory protein-2 (MIP-2) were measured using enzymelinked immunosorbent assay (ELISA) kits (R\&D Systems, Minneapolis, MN) according to the manufacturer's instructions. 
TABLE 1: Oligonucleotide primers employed.

\begin{tabular}{|c|c|c|c|c|}
\hline Gene & & Primer sequence & $\operatorname{Tm}{ }^{\circ} \mathrm{C}$ & Amplicon size (bp) \\
\hline \multirow{2}{*}{ 9s rRNA } & $\mathrm{F}$ & 5'-ATCCGCCAACGTCACATT-3' & 57.6 & \multirow{2}{*}{115} \\
\hline & $\mathrm{R}$ & $5^{\prime}$-CCGCCGCCATAAGGAGAAC-3' & 64.5 & \\
\hline \multirow{2}{*}{ CD36 } & $\mathrm{F}$ & $5^{\prime}$-CAGTCGGAGACATGCTTATTGAG-3' & 60.7 & \multirow{2}{*}{151} \\
\hline & $\mathrm{R}$ & 5'-TTTGCCACGTCATCTGGGTTT-3' & 62.5 & \\
\hline \multirow{2}{*}{ COX-2 } & $\mathrm{F}$ & 5'-TGTGACTGTACCCGGACTGG-3' & 63.0 & \multirow{2}{*}{233} \\
\hline & $\mathrm{R}$ & $5^{\prime}$-TGCACATTGTAAGTAGGTGGAC-3' & 60.0 & \\
\hline \multirow{2}{*}{ FABP4 } & $\mathrm{F}$ & 5'-GGGGCCAGGCTTCTATTCC-3' & 61.8 & \multirow{2}{*}{114} \\
\hline & $\mathrm{R}$ & 5'-GGAGCTGGGTTAGGTATGGG-3' & 61.1 & \\
\hline \multirow{2}{*}{ GAPDH } & $\mathrm{F}$ & 5'-GGACGCATTGGTCGTCTGG-3' & 63.0 & \multirow{2}{*}{204} \\
\hline & $\mathrm{R}$ & 5'-TTTGCACTGGTACGTGTTGAT-3' & 60.2 & \\
\hline \multirow{2}{*}{ IL-12 p40 } & $\mathrm{F}$ & 5'-CAAGGCTGTTCACATTATCCCA-3' & 60.3 & \multirow{2}{*}{107} \\
\hline & $\mathrm{R}$ & 5'-CCAGTGTGGTCATGGACTTTC-3' & 60.6 & \\
\hline \multirow{2}{*}{ MCP-1 } & $\mathrm{F}$ & 5'-TTAAAAACCTGGATCGGAACCAA-3' & 60.1 & \multirow{2}{*}{121} \\
\hline & $\mathrm{R}$ & 5'-GCATTAGCTTCAGATTTACGGGT-3' & 60.7 & \\
\hline \multirow{2}{*}{ NOS2 } & $\mathrm{F}$ & 5'-ACATCGACCCGTCCACAGTAT-3' & 62.7 & \multirow{2}{*}{177} \\
\hline & $\mathrm{R}$ & 5'-CAGAGGGGTAGGCTTGTCTC-3' & 61.0 & \\
\hline \multirow{2}{*}{ NOX4 } & $\mathrm{F}$ & 5'-TGCCTGCTCATTTGGCTGT-3' & 62.2 & \multirow{2}{*}{180} \\
\hline & $\mathrm{R}$ & 5'-CCGGCACATAGGTAAAAGGATG-3' & 60.8 & \\
\hline \multirow{2}{*}{ PPAR- $\gamma$} & $\mathrm{F}$ & 5'-CCATTCTGGCCCACCAAC-3' & 66.5 & \multirow{2}{*}{479} \\
\hline & $\mathrm{R}$ & 5'-CTGAAACCGACAGTACTG-3' & 53.8 & \\
\hline \multirow{2}{*}{ TNF- $\alpha$} & $\mathrm{F}$ & 5'-CCTGTAGCCCACGTCGTAG-3' & 61.5 & \multirow{2}{*}{148} \\
\hline & $\mathrm{R}$ & $5^{\prime}$-GGGAGTAGACAAGGTACAACCC-3' & 61.4 & \\
\hline
\end{tabular}

2.11. RNA Isolation and Quantitative Real-Time RT-PCR. Cells pelleted from BAL fluid were resuspended in DMEM supplemented with $10 \%$ fetal bovine serum, allowed to adhere to tissue culture-treated six-well plates for $1 \mathrm{~h}$, and then washed twice to remove nonadherent cells. Adherent alveolar macrophages were lysed, and RNA was isolated using RNeasy Mini kit (Qiagen, Valencia, CA), with cDNA being generated from $100 \mathrm{ng}$ of total RNA using MultiScribe reverse transcriptase (Applied Biosystems, Foster City, CA) employing random and oligo dT primers. Real-time quantitative PCR was performed using $100 \mathrm{ng}$ cDNA with 2X SYBR Green Master mix (Applied Biosystems) and specific primers for the genes of interest (Table 1). These experiments were performed on an $\mathrm{AB} 7500$ fast thermal cycler using a three-step protocol employing the melting curve method. The average of each gene cycle threshold $\left(C_{t}\right)$ was determined for each experiment. Relative cDNA levels $\left(2^{-\Delta \Delta \mathrm{Ct}}\right)$ for the genes of interest were determined by using the comparative $C_{t}$ method, which generates the $\Delta \Delta \mathrm{Ct}$ as the difference between the gene of interest and the housekeeping genes glyceraldehyde-3-phosphate dehydrogenase (GAPDH) and 9s rRNA for each sample. Each averaged experimental gene expression sample was compared to the averaged control sample, which was set to 1 .

2.12. Transient Transfection Assay. PPAR- $\gamma$ activity in A549 cells (ATCC, Rockville, MD) was determined as previously described [18]. Briefly, cells were transiently co-transfected either with a plasmid containing the luciferase gene under regulation by four Gal4 DNA-binding elements $\left(\mathrm{UAS}_{\mathrm{G}} \times\right.$
4 TK-luciferase) and a plasmid containing the PPAR- $\gamma$ ligand-binding domain fused to the Gal4 DNA-binding domain or with the luciferase gene under control of the peroxisome proliferator response element (PPRE) isolated from the fatty acid transport protein. All transfections were performed using Lipofectamine 2000 (Invitrogen) according to the manufacturer's instructions. Following treatment with test compounds, activation was measured using the DualLuciferase Reporter Assay System (Promega, Madison, WI) according to the manufacturer's instructions.

2.13. Transcription Factor DNA-Binding Activity Assay. Nuclear proteins were extracted using a nuclear extraction kit (Active Motif, Carlsbad, CA) according to the manufacturer's protocol. The protein concentration was determined using the BCA Protein Assay kit (Pierce). Nuclear extracts were used to quantify DNA-binding activity of PPAR- $\gamma$, nuclear factor (erythroid-derived 2)-like 2 (Nrf2), and the p65 subunit of NF- $\kappa \mathrm{B}$ using ELISA-based TransAM kits (40096, 40696, and 50296; Active Motif) according to the manufacturer's instructions.

2.14. Molecular Modeling and Computer Simulations of Binding of $\mathrm{OA}-\mathrm{NO}_{2}$ with PPAR- $\gamma$. In silico construction of OA-NO $\mathrm{NO}_{2}$ was carried out using Chem Office (ChemDraw and Chem3D; CambridgeSoft Corp., Cambridge, MA). To avoid steric hindrance and clashes that can appear in the building process, the models obtained were subjected to geometry optimization using GaussView with a protocol of 300 steps of conjugate gradients. Each model then was optimized using 
a semi-empirical method such as PM3 as implemented in the Gaussian98 package of programs.

Autodock 4.2 (with Lamarckian Genetic Algorithm) or ArgusLab 4 was used to generate the starting complexes. An elitism value of 1 was used, together with probabilities of mutation and crossing-over of 0.03 and 0.07 , respectively. From the best solutions obtained according to these parameters, those defined by the user as exhibiting the best probabilities-in our case, 0.07 -were further refined by a local search method. Autodock defines the conformational space implementing grids over the entire space of possible solutions. With the aim of testing the ability of Autodock to converge into solutions that are inside the PPAR- $\gamma$ ligandbinding domain, a grid of $70 \AA$ per side with $0.4 \AA$ spacing between points was set up in such a way that it covered both the external surface and the internal cavity of the PPAR$\gamma$ ligand-binding domain. The following procedure was employed for the OA- $\mathrm{NO}_{2}$-PPAR- $\gamma$ ligand-binding domain docking simulations: 150 runs were done for each OA$\mathrm{NO}_{2}$-PPAR- $\gamma$ ligand-binding domain. At the end of each run, the complexes were separated into clusters according to their lowest root mean square deviation (RMSD), and the best score value based on a free empiric energy function was determined. Cluster complexes whose average score was $-11.50 \mathrm{kcal}-\mathrm{mol} / \mathrm{L}$ with respect to the best energy obtained in that run were selected. The selected final complexes were optimized using the semi-empirical PM3 method as a refining procedure with Gaussian98.

Constant-volume, constant-temperature molecular dynamics (MD) simulations of the complexes were performed on the Discover, version 2.7 (Biosym Technologies, Inc., San Diego, CA) and MD simulation programs in Chem Office. Energy minimizations were conducted for two systems, both of which assumed 1 molecule of $\mathrm{OA}-\mathrm{NO}_{2}, 1$ molecule of PPAR- $\gamma$, and water molecules. The systems simulated were; (i) $\mathrm{OA}-\mathrm{NO}_{2}$ and PPAR- $\gamma$ separated from each other by a distance greater than the non-bonded cutoff distance ( $>8.5 \AA$ ); (ii) OA- $\mathrm{NO}_{2}$ complexed with the PPAR- $\gamma$ ligandbinding domain. Each molecular system was contained in a box size of $25.0 \times 25.0 \times 37.0 \AA$ with periodic boundary conditions. The step size was 2 femtoseconds (fsec). To start the simulations, different seed numbers were used for initial Maxwellian velocity distribution for each system. Simulations were continued and the coordinates were saved for analysis every 2 fsec.

2.15. Statistical Analysis. Data are presented as mean \pm SD. Differences between groups were analyzed using ANOVA, followed by a Bonferroni multiple comparison test using GraphPad Prism 5.03 (GraphPad Software, La Jolla, CA). $P<0.05$ was considered significant.

\section{Results}

3.1. In Silico Binding of $\mathrm{OA}-\mathrm{NO}_{2}$ to PPAR- $\gamma$. Although the crystal structure of $\mathrm{LNO}_{2}$ bound to the PPAR- $\gamma$ ligand binding site has been reported [19], no similar information is available for $\mathrm{OA}-\mathrm{NO}_{2}$. We accordingly used in silico methods to determine the likely binding mode for this compound. As shown in Figures $1(\mathrm{a})$ and $1(\mathrm{~b}), \mathrm{OA}-\mathrm{NO}_{2}$ is well accommodated within the PPAR- $\gamma$ ligand-binding site, with best pose energy of $-11.50 \mathrm{kcal} / \mathrm{mol}$, and exhibits the appropriate interactions and hydrogen bonds with the PPAR- $\gamma$ amino acid residues (ARG 288, GLN 286, HIS 449, and TYR 473) that are known to be important for PPAR- $\gamma$ activation.

3.2. $\mathrm{OA}-\mathrm{NO}_{2}$ Activates PPAR- $\gamma$ In Vitro. To confirm the ability of NFAs to activate PPAR- $\gamma$ we utilized the GAL4 reporter system in A549 airway epithelial cells. Transfected cells were treated with $0.1,1$, or $5 \mu \mathrm{M}$ concentrations of $\mathrm{OA}-\mathrm{NO}_{2}$ or, as a positive control, of the synthetic PPAR- $\gamma$ agonist rosiglitazone. Each compound demonstrated dosedependent activation as a result of binding to the construct's PPAR- $\gamma$ ligand-binding domain, with similar activation for given molar concentrations (Figure 1(c)). To demonstrate activation of endogenous PPAR- $\gamma$, A549 cells were similarly transfected with the luciferase gene under control of a PPAR response element. This assay likewise demonstrated dosedependent activation by both $\mathrm{OA}-\mathrm{NO}_{2}$ and rosiglitazone (Figure 1(d)).

3.3. Pulmonary Administration of $\mathrm{OA}-\mathrm{NO}_{2}$ Diminishes Severity of LPS-Induced Lung Inflammation. Pulmonary inflammation is a crucial feature of ALI. Since the nuclear receptor PPAR- $\gamma$ is known to exert a variety of anti-inflammatory effects and unsaturated long-chain NFAs are activating ligands for PPAR- $\gamma$, we hypothesized that pulmonary delivery of an NFA would diminish the severity of ALI. To test this hypothesis, we utilized a well-established murine model of ALI induced by i.t. administration of $50 \mu \mathrm{g}$ of LPS. Thirty min after LPS injection, $50 \mu \mathrm{g}$ of $\mathrm{OA}-\mathrm{NO}_{2}$ in $10 \% \mathrm{DMSO}$ was delivered to the lungs via the i.t. route. Control mice received vehicle without NFA. After a further $5.5 \mathrm{~h}$ the mice were euthanized, the lower right lobe excised for assessment of edema by wet:dry weight ratio, BAL fluid collected, and the lungs excised for histopathological examination and measurement of inflammation-association molecular markers. Plasma was obtained at the same time.

A prominent aspect of pulmonary inflammation is infiltration of neutrophils (polymorphonuclear leukocytes; PMNs) into the lungs and thus into BAL fluid. We observed an LPS-induced increase in the total number of cells in BAL fluid (Figure 2(a)), and differential staining indicated that neutrophils accounted for most of the increase (Figure 2(b)). Both increases were significantly attenuated by $\mathrm{OA}-\mathrm{NO}_{2}$ treatment. Similar results were seen for measurements of myeloperoxidase in both lung (Figure 2(c)) and BAL fluid (Figure 2(d)). MPO is found in the pulmonary system in association with PMNs and is thus a marker for their presence. These results were confirmed by direct microscopic examination of BAL fluid (Figure 2(e)).

Inflammation is also characterized by oxidant stress, which directly injures lung tissues. Oxidant stress reflects production of reactive oxygen species such as $\mathrm{H}_{2} \mathrm{O}_{2}$ and superoxide, predominantly by macrophages and neutrophils, and of the reactive nitrogen species NO by a variety of cell types. As expected, measurement of $\mathrm{H}_{2} \mathrm{O}_{2}$ demonstrated 


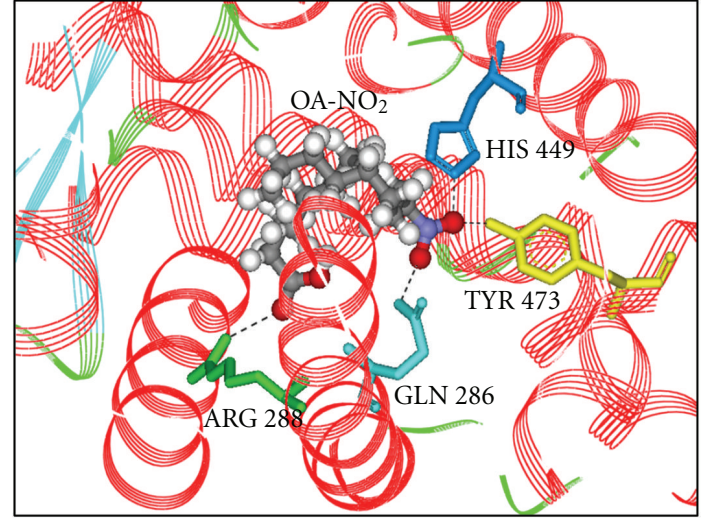

(a)

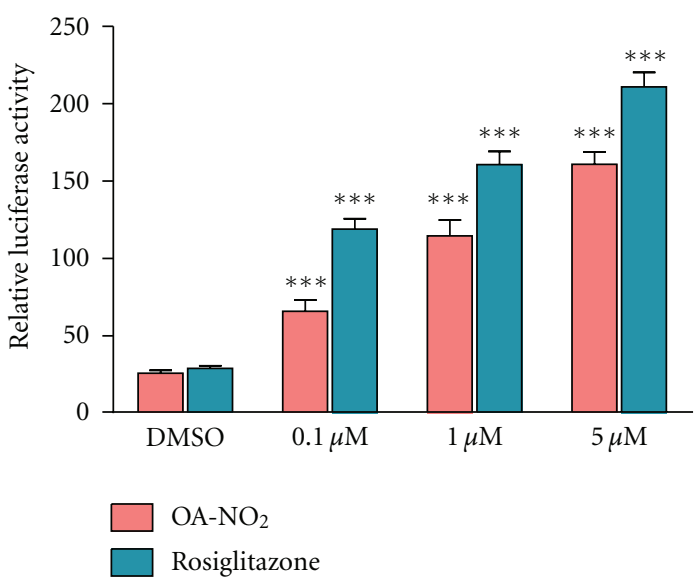

(c)

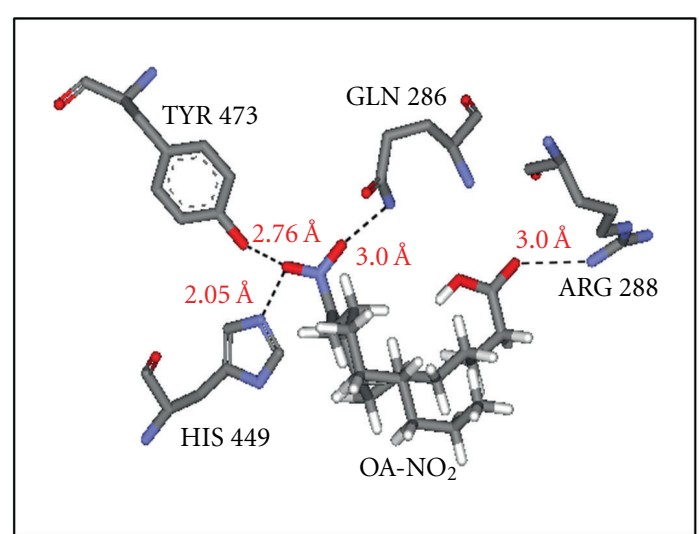

(b)

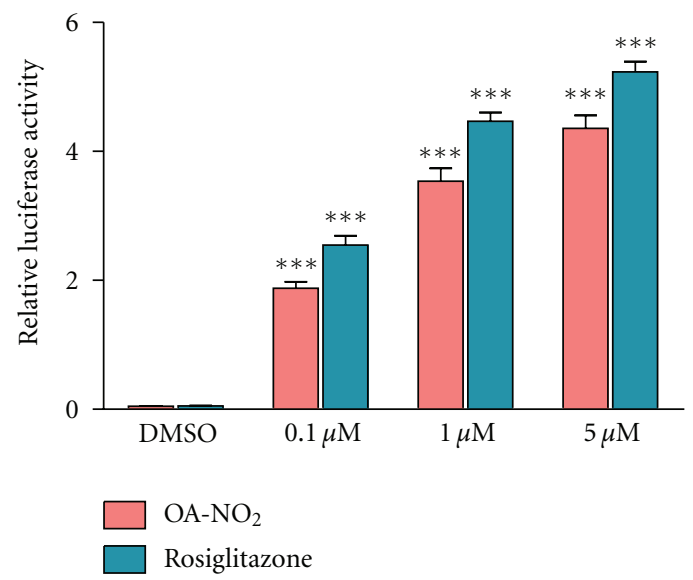

(d)

FIgURE 1: OA- $\mathrm{NO}_{2}$ activates PPAR- $\gamma$ in airway epithelial cells. Binding of OA- $\mathrm{NO}_{2}$ to the PPAR- $\gamma$ ligand-binding domain was modeled in silico. Results are presented as (a) space-filling representation; (b) schematic representation showing interactions of PPAR- $\gamma$ residues with specific groups in the $\mathrm{OA}-\mathrm{NO}_{2}$ ligand. Hydrogen bonds are indicated by dotted lines. A549 cells were transiently transfected with pRLSV40 and with one of the following constructs: (c) PPAR-dependent luciferase reporter, pFATPluc; (d) PPAR- $\gamma$ GAL4 reporter system $\left(\mathrm{UAS}_{\mathrm{G}} \times 4\right.$ TK-luciferase + GAL4-PPAR- $\gamma$ ). Cells were then incubated with vehicle (DMSO), OA-NO $(0.1-5 \mu \mathrm{M})$, or rosiglitazone $(0.1-5 \mu \mathrm{M})$. After $24 \mathrm{~h}$, luciferase activity was measured with a dual luciferase activity kit and normalized to that of Renilla luciferase. Data are representative of one of two independent experiments; $n=6$; ${ }^{* * *} P<0.001$ versus vehicle.

a large increase following LPS administration that was reduced by $\mathrm{OA}-\mathrm{NO}_{2}$ treatment (Figure $2(\mathrm{f})$ ). Similar results were seen for nitrate, the end product of $\mathrm{NO}$ metabolism (Figure 2(g)). Levels of the lipid oxidation product MDA that provides an index of overall oxidative stress, and MDA levels followed the same pattern as the other two markers of oxidant generation (Figure $2(\mathrm{~h})$ ).

Inflammation in ALI is likewise associated with release of proinflammatory cytokines and chemokines by neutrophils, macrophages, and other cells. We measured the proinflammatory cytokines TNF- $\alpha$ (Figure 2(i)) and IL-6 (Figure $2(\mathrm{j})$ ), the chemokine $\mathrm{KC}$, which activates and attracts neutrophils (Figure 2(k)), and the related chemokine MIP2, which has effects similar to KC (Figure 2(l)). Plasma levels of all four markers were greatly increased by LPS administration, but this increase was significantly reduced by $\mathrm{OA}-\mathrm{NO}_{2}$ treatment.
3.4. Pulmonary Administration of $\mathrm{OA}-\mathrm{NO}_{2}$ Diminishes Capillary Permeability and Severity of LPS-Induced Lung Injury. Increased capillary permeability results in lung edema, a driving force for the hypoxemia that is observed in ALI. It also allows escape of plasma proteins into the alveolar space, which can then be detected in BAL fluid. We find that $\mathrm{OA}-\mathrm{NO}_{2}$ treatment attenuates the LPS-induced increase in BAL fluid protein concentration (Figure 3(a)). The increased vascular permeability following LPS administration allowed EBD to extravasate from the vasculature into the lung parenchyma, turning these lungs deep blue $(\sim 0.3 \mu \mathrm{g}$ dye per g lung). This extravasation of EBD was significantly reduced by $\mathrm{OA}-\mathrm{NO}_{2}$ treatment, however, resulting in only a pale blue appearance of the lung $(\sim 0.17 \mu \mathrm{g}$ dye per $\mathrm{g}$ lung; Figure 3(c)). The lung edema that results from capillary permeability is reflected in the wet:dry weight ratio, and LPSinduced increases in this parameter were also reduced by 


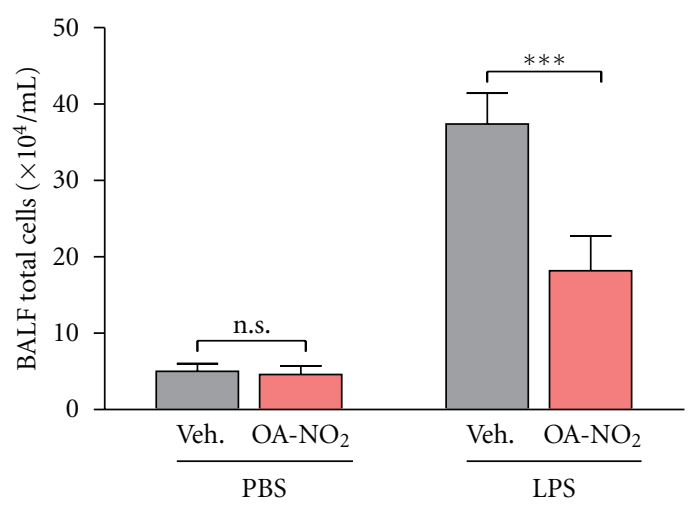

(a)

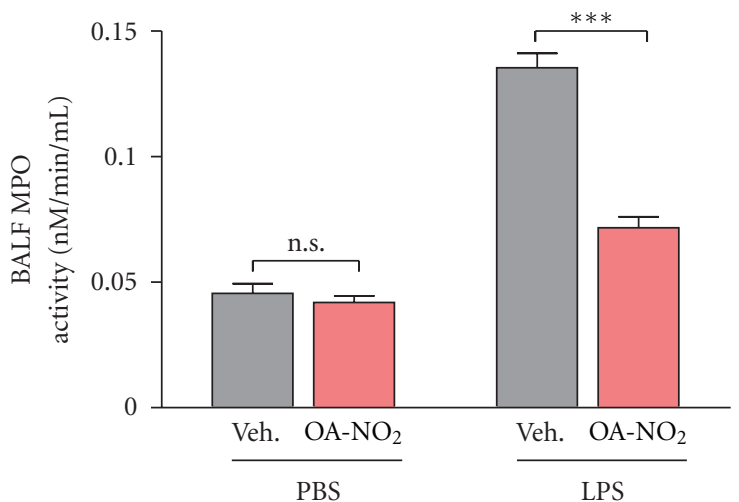

(c)

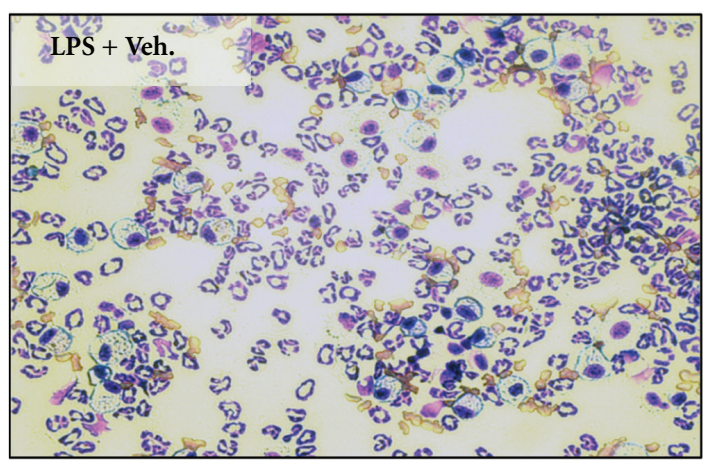

(e)

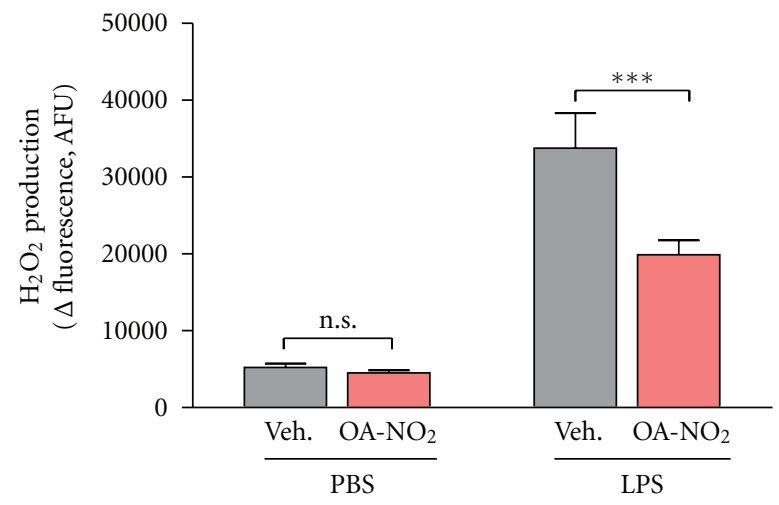

(f)

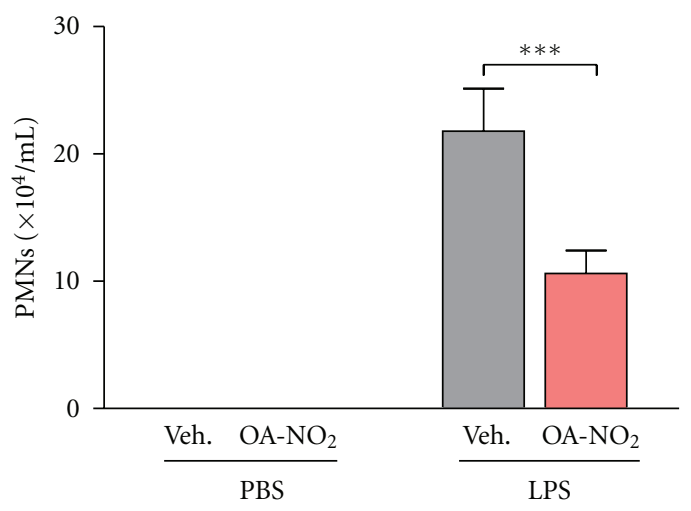

(b)

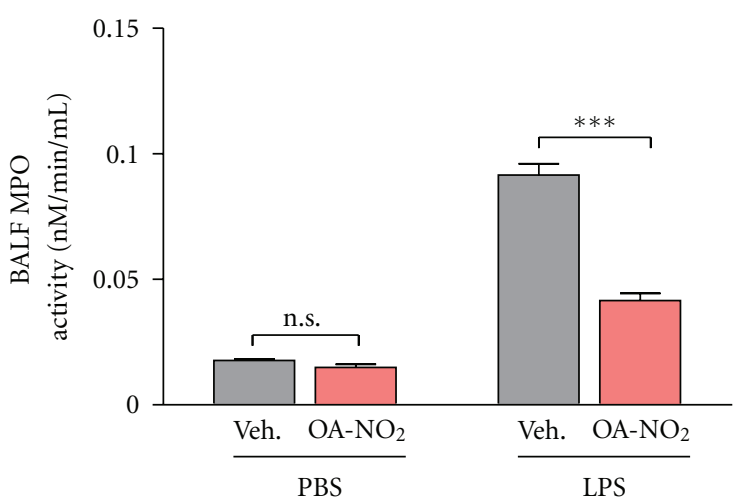

(d)
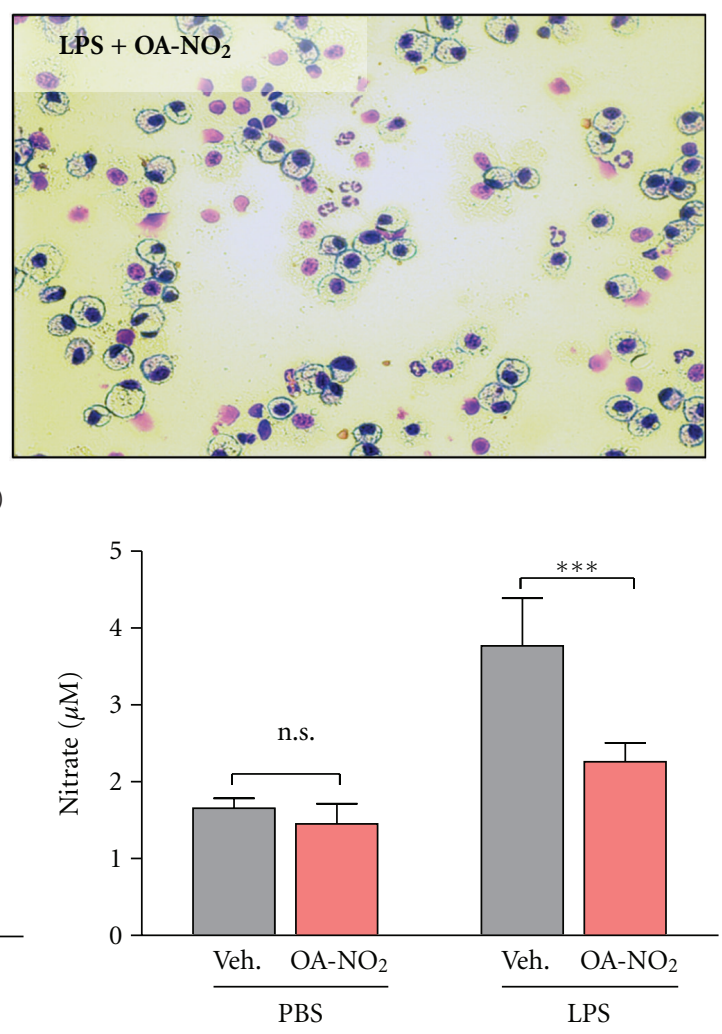

(g)

Figure 2: Continued. 


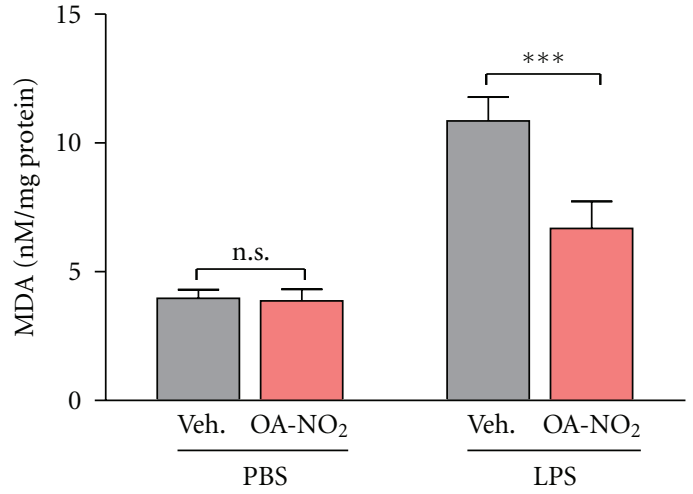

(h)

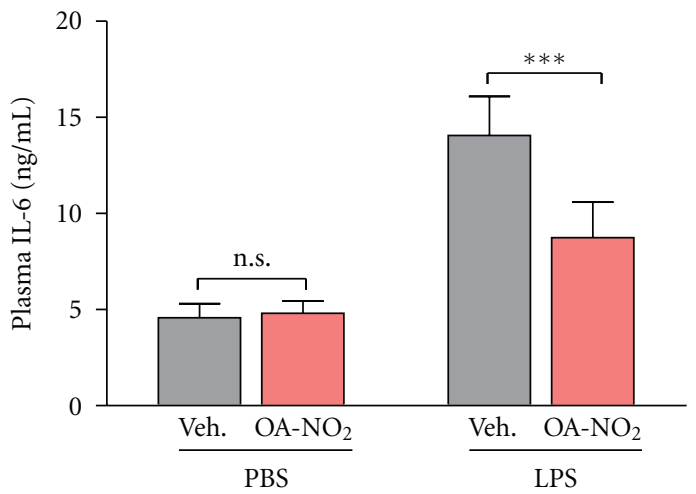

(j)

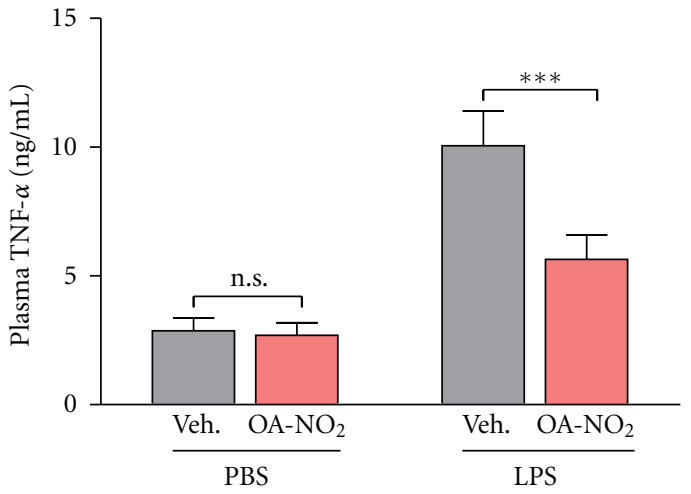

(i)

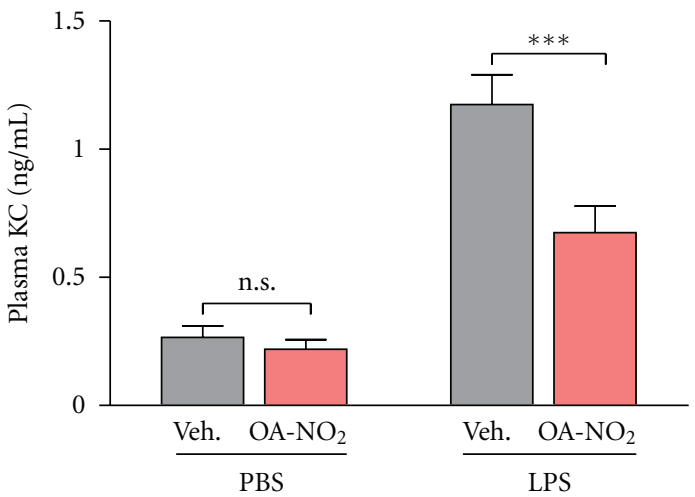

$(\mathrm{k})$

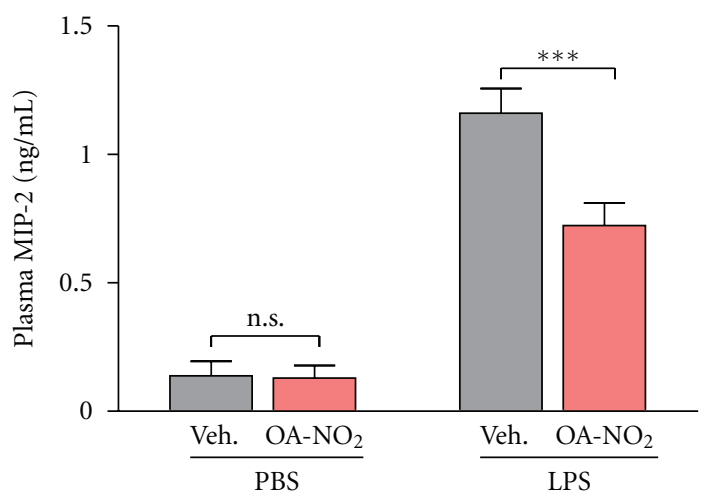

(1)

FIgURe 2: Pulmonary delivery of OA-NO $\mathrm{N}_{2}$ reduces LPS-induced lung inflammation. Induction of ALI by i.t. injection of LPS (50 $\mu \mathrm{g}$ ) was followed $30 \mathrm{~min}$ later by i.t. administration $(50 \mu \mathrm{L})$ of $\mathrm{OA}-\mathrm{NO}_{2}(50 \mu \mathrm{g})$ or vehicle $(10 \% \mathrm{DMSO})$. After a further $5.5 \mathrm{~h}$, BAL fluid, plasma, and lung samples were obtained. (a) Total cell and (b) neutrophil number in BAL fluid. Myeloperoxidase activity in (c) lung tissue and (d) BAL fluid. (e) Microscopic examination following staining of BAL fluid. (f) $\mathrm{H}_{2} \mathrm{O}_{2}$ production, (g) nitrate concentration, and (h) malonaldehyde/protein ratio in lung. Plasma levels of (i) TNF- $\alpha$, (j) IL-6, (k) KC, and (l) MIP-2. Data are representative of one of two independent experiments with $n=6-8$ mice per group; ${ }^{* * *} P<0.001$.

OA-NO $\mathrm{NO}_{2}$ treatment (Figure 3(b)). Direct histopathological examination of the lung following H\&E staining further confirmed significant lung inflammation and injury in mice treated with vehicle but much less severe abnormalities in those that had received $\mathrm{OA}-\mathrm{NO}_{2}$ (Figure 3(d)).

3.5. $\mathrm{OA}-\mathrm{NO}_{2}$ Produces Anti-Inflammatory Alterations in Activity of PPAR- $\gamma, N F-\kappa B$, and Nrf2. We propose that
NFAs exert many of their anti-inflammatory effects by activating PPAR- $\gamma$, which is known to decrease activity of the proinflammatory transcription factor NF- $\kappa$ B. PPAR- $\gamma$ promotes transcription of the antioxidant factor $\mathrm{Nrf} 2$, which in turn upregulates PPAR- $\gamma$ expression in a positive feedback loop $[20,21]$. To test our hypothesis, we examined the effects of OA- $\mathrm{NO}_{2}$ treatment on activity of PPAR- $\gamma$, NF$\kappa \mathrm{B}$, and $\mathrm{Nrf} 2$. When followed by vehicle treatment, i.t. LPS 


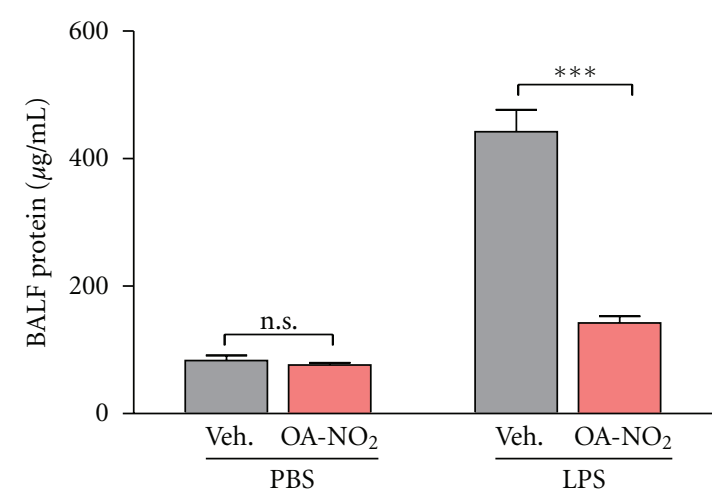

(a)
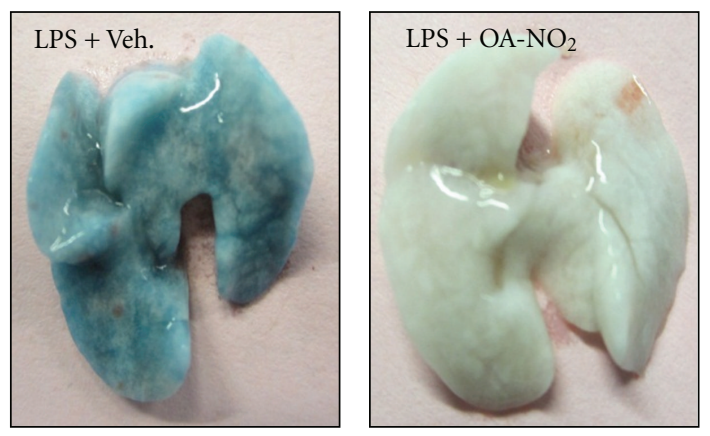

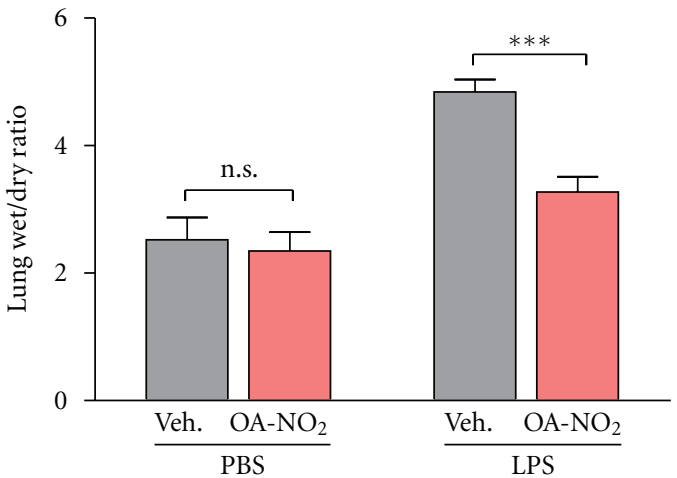

(b)

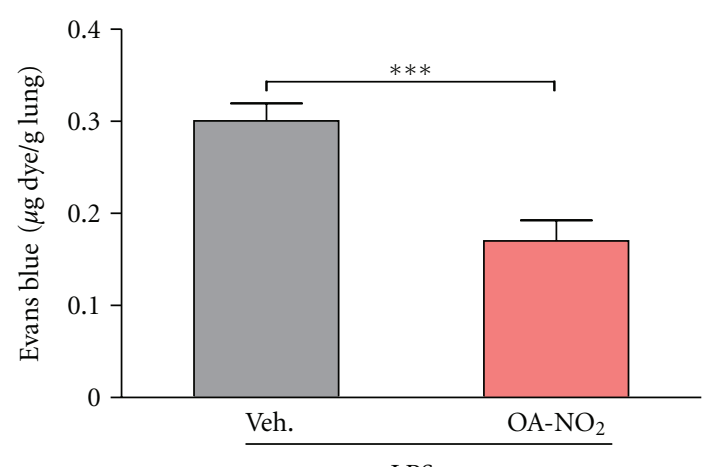

LPS

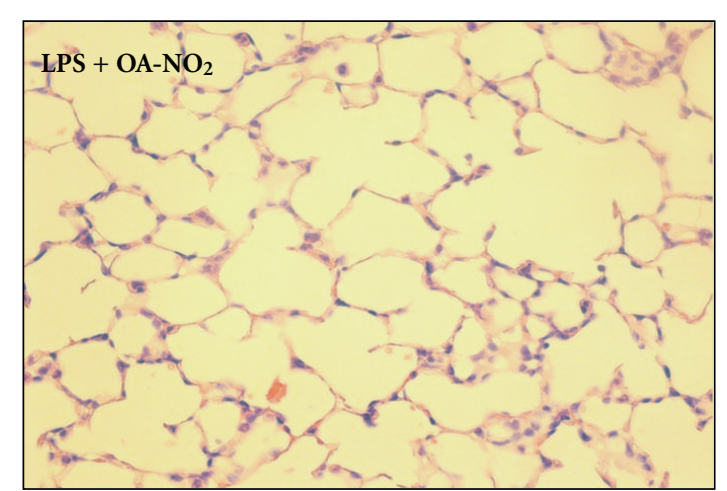

(d)

FIGURE 3: Pulmonary delivery of OA-NO 2 reduces LPS-induced lung injury. Induction of ALI by i.t. injection of LPS (50 $\mu$ g) was followed 30 min later by i.t. administration $(50 \mu \mathrm{L})$ of $\mathrm{OA}-\mathrm{NO}_{2}(50 \mu \mathrm{g})$ or vehicle $(10 \% \mathrm{DMSO})$. After a further $5.5 \mathrm{~h}$, BAL fluid and lung samples were obtained. (a) Protein concentration in BAL fluid. (b) Ratio of lung wet:dry weight. (c) Extravasation of Evans Blue dye into the lung following intravenous injection was photographed and quantitated by spectrophotometry. (d) The lung was examined histologically following H\&E staining. Data are representative of one of two independent experiments with $n=6-8$ mice per group; ${ }^{* * *} P<0.001$.

upregulated the DNA-binding activity of NF- $\kappa \mathrm{B}$, as expected (Figure 4(c)) but decreased activity of PPAR- $\gamma$ (Figure 4(a)) and $\mathrm{Nrf} 2$ (Figure $4(\mathrm{~b})$ ). OA-NO $\mathrm{N}_{2}$ treatment, however, not only diminished the increase in NF- $\kappa \mathrm{B}$ activity but also increased the DNA-binding activity of PPAR- $\gamma$ and Nrf2. Under noninflammatory conditions, $\mathrm{OA}-\mathrm{NO}_{2}$ treatment increased PPAR- $\gamma$ activity but had no significant effect on basal levels of NF- $\kappa \mathrm{B}$ or Nrf2 activity. Given the role of NFAs as PPAR- $\gamma$ agonists and the known anti-inflammatory and antioxidant activities of PPAR- $\gamma$, many exerted through inhibition of NF- $\kappa$ B activity and upregulation of Nrf2, these data support the concept that NFAs act in part via PPAR- $\gamma$ activation.

3.6. $\mathrm{OA}-\mathrm{NO}_{2}$ Decreases Inflammatory Response of Alveolar Macrophages. Alveolar macrophages play a central role in regulation of the lung's immune system. When activated by stimuli such as LPS, they generate oxidants and secrete molecules that attract neutrophils and other immune cells to the lung. As PPAR- $\gamma$ is known to play a major role 


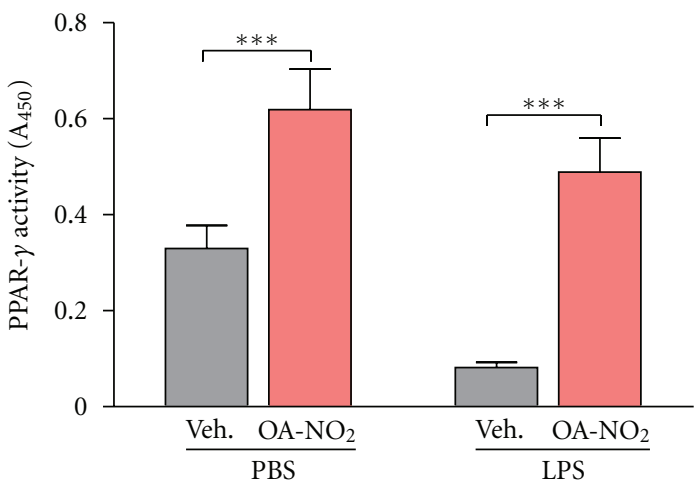

(a)

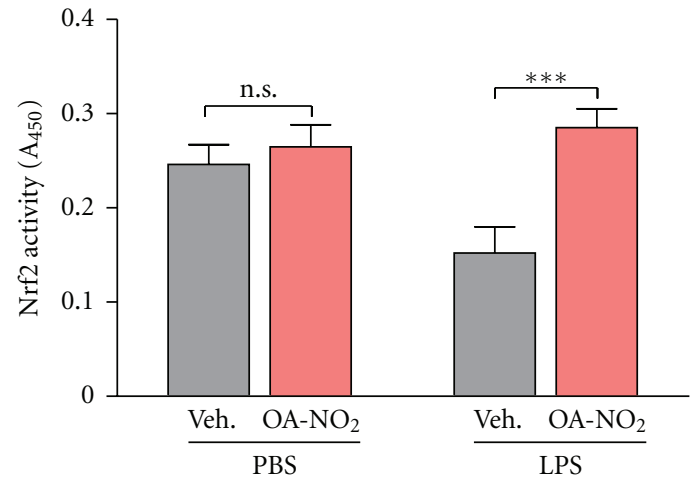

(b)

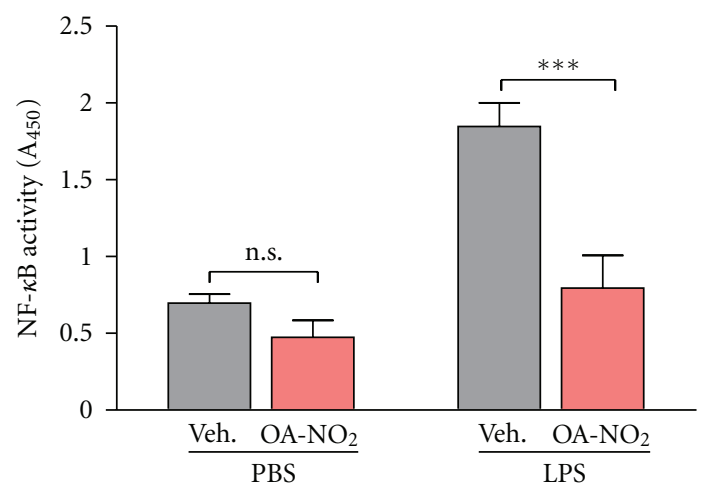

(c)

FIGURE 4: $\mathrm{OA}-\mathrm{NO}_{2}$ reverses LPS-induced changes in transcription factor activity. Induction of ALI by i.t. injection of LPS (50 $\mu$ g) was followed $30 \mathrm{~min}$ later by i.t. administration $(50 \mu \mathrm{L})$ of $\mathrm{OA}-\mathrm{NO}_{2}(50 \mu \mathrm{g})$ or vehicle $(10 \% \mathrm{DMSO})$. After another $5.5 \mathrm{~h}$ lungs were excised and DNA-binding activity of the transcription factors (a) PPAR- $\gamma$, (b) Nrf2, and (c) NF- $\kappa$ B was determined. Data are representative of one of two independent experiments with $n=6-8$ mice per group; ${ }^{* * *} P<0.001$.

in modulating activation of alveolar macrophages [22], we investigated the ability of NFAs to suppress LPS-induced activation of these cells. Specifically, mice were treated with LPS and either vehicle or OA- $\mathrm{NO}_{2}$ as previously described. Alveolar macrophages were then isolated and their RNA extracted for determination of relevant gene expression. Results (Figure 5) demonstrate significant suppression of the proinflammatory cytokines TNF- $\alpha$ and interleukin-12 (IL-12) and the chemokine MCP-1. Downregulation was also observed for the inducible form of nitric oxide synthase (iNOS; NOS2) and the superoxide-generating enzyme NADPH oxidase 4 (NOX4), both of which contribute to oxidative stress. $\mathrm{OA}-\mathrm{NO}_{2}$ treatment also reduced alveolar macrophage expression of cyclooxygenase 2 (COX-2), which synthesizes proinflammatory prostaglandins. Conversely, OA- $\mathrm{NO}_{2}$ upregulated expression of PPAR- $\gamma$, and the PPAR$\gamma$ target genes fatty acid binding protein 4 (FABP4) and $\mathrm{CD} 36$, a receptor that facilitates macrophage phagocytosis of apoptotic and senescent neutrophils and thereby contributes to the resolution of inflammation. All these measurements confirm the ability of NFA treatment in vivo to suppress the activated, proinflammatory phenotype of alveolar macrophages.

\section{Discussion}

Our results establish that delivery of $\mathrm{OA}-\mathrm{NO}_{2}$ directly to the lung significantly reduces the severity of pulmonary inflammation and injury. We also find that treatment with $\mathrm{OA}-\mathrm{NO}_{2}$ suppresses the activated phenotype of alveolar macrophages, key cells in the regulation of pulmonary inflammation. In the lung, LPS-induced increase in activity of the proinflammatory transcription factor NF- $\kappa \mathrm{B}$ is largely blocked, as are LPS-induced decreases of PPAR- $\gamma$ and the antioxidant transcription factor Nrf2. Indeed, PPAR- $\gamma$ activity is increased over basal levels in both inflammatory and noninflammatory conditions. Upregulation of Nrf2 expression and activity may account for much of the antioxidant activity of PPAR- $\gamma$ and consequent reduction in inflammation-associated oxidative injury [20,21].

This appears to be the first study of NFAs' ability to reduce the severity of ALI and one of very few to investigate the protective anti-inflammatory actions of NFAs in an animal model of any disease. Borniquel and colleagues have recently obtained results in a murine model of inflammatory bowel disease that are similar to ours in ALI [23], finding that $\mathrm{OA}-\mathrm{NO}_{2}$ decreased disease severity and the increase in $\mathrm{NF}-\kappa \mathrm{B}$ expression while increasing expression of PPAR $-\gamma$. 


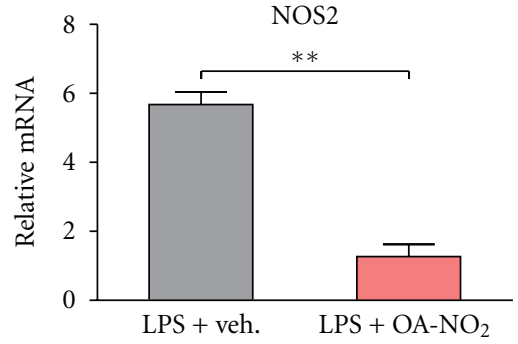

(a)

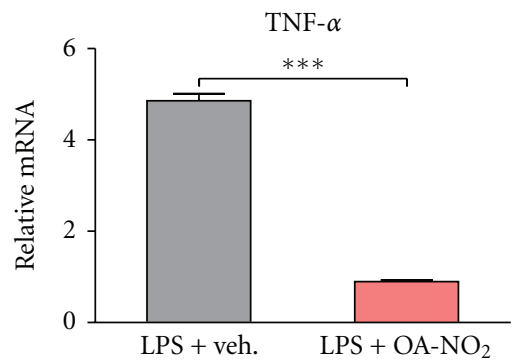

(d)

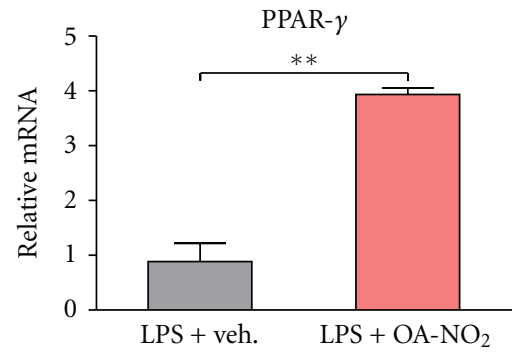

(g)

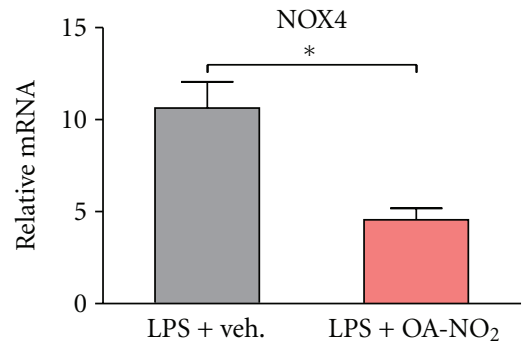

(b)

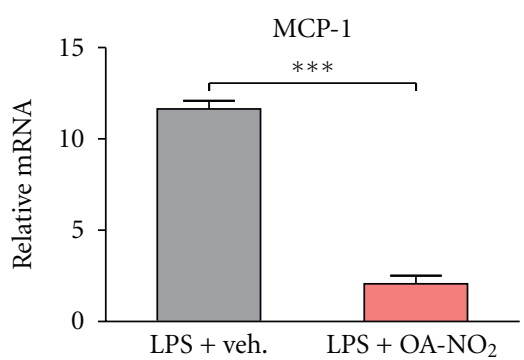

(e)

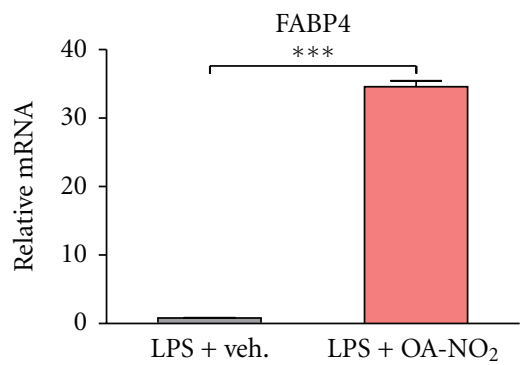

(h)

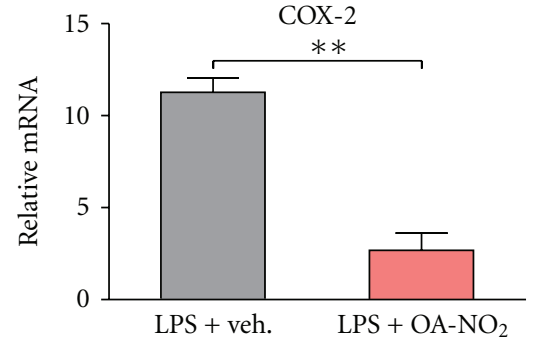

(c)

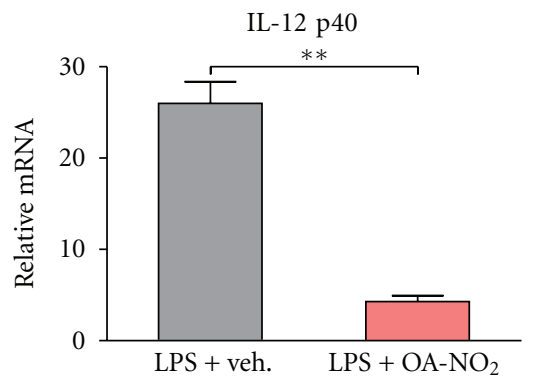

(f)

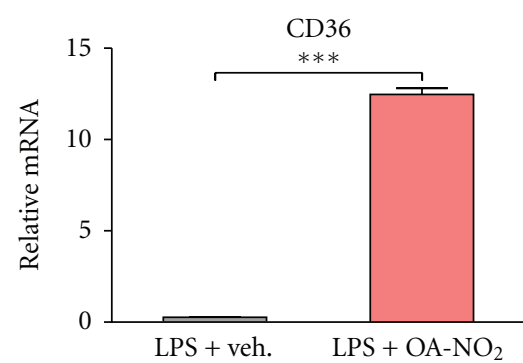

(i)

FIGURE 5: OA- $\mathrm{NO}_{2}$ reduces inflammatory phenotype in LPS-activated alveolar macrophages. Induction of ALI by i.t. injection of LPS $(50 \mu \mathrm{g})$ was followed 30 min later by i.t. administration $(50 \mu \mathrm{L})$ of $\mathrm{OA}-\mathrm{NO}_{2}(50 \mu \mathrm{g})$ or vehicle $(10 \%$ DMSO). After another $5.5 \mathrm{~h}$ BAL fluid was obtained. Alveolar macrophages were isolated from the BAL fluid and plated in DMEM + 10\% FBS. After $1 \mathrm{~h}$, RNA was isolated and expression of the indicated genes was determined using real-time PCR; results were normalized to values for the housekeeping genes glyceraldehyde-3-phosphate dehydrogenase (GAPDH) and 9s rRNA. Data are representative of one of two independent experiments with $n$ = 6-8 mice per group; ${ }^{*} P<0.05 ;{ }^{* *} P<0.01 ;{ }^{* *} P<0.001$.

Significantly, the increase in PPAR- $y$ expression was abolished by simultaneous administration of a PPAR- $\gamma$ antagonist. $\mathrm{OA}-\mathrm{NO}_{2}$ was also found to reduce infarct size in cardiac ischemia-reperfusion injury [24]. This was accompanied by a reduction in NF- $\kappa$ B activity but a potential role for PPAR- $\gamma$ was not investigated. Beneficial effects of $\mathrm{OA}-\mathrm{NO}_{2}$, together with reduced inflammation, have also been seen in renal ischemia/reperfusion injury [25]. It appears likely that a number of other inflammatory conditions might also benefit from NFA treatment.

Activation of the nuclear hormone receptor PPAR- $\gamma$ has been shown to reduce the severity of LPS-induced ALI $[5,9]$, and NFAs are known to activate PPAR- $\gamma[11$, 12]. That this activation reflects binding to the ligand binding domain is demonstrated both by ability of NFAs to displace the synthetic ligand rosiglitazone [12] and by the elucidated crystal structure of $\mathrm{LNO}_{2}$ bound to this site [19]. We therefore suggest that the protective effects we observe are mediated largely by activation of PPAR- $\gamma$. Such activation appears adequate to account for most of our observations, including increased activity and expression of both PPAR- $\gamma$ itself and the antioxidant transcription factor Nrf2, which both upregulates and is upregulated by PPAR- $\gamma$ $[20,21]$, as well as decreased activity of the proinflammatory transcription factor NF- $\kappa$ B.

Initial studies suggested that $\mathrm{OA}-\mathrm{NO}_{2}$ and $\mathrm{LNO}_{2}$ were present in normal human plasma at concentrations exceeding $0.1 \mu \mathrm{M}$, which in conjunction with their measured binding affinity would raise the possibility that they were endogenous PPAR- $\gamma$ agonists [11]. Later studies from another group, however, have suggested concentrations below $1 \mathrm{nM}$ [26]. Notably, both studies were performed with plasma from healthy subjects and do not reflect the increase in NFA concentrations anticipated in inflammatory conditions. This controversy nevertheless has only limited relevance to our studies, which address pharmacological effects of 
exogenously delivered $\mathrm{OA}-\mathrm{NO}_{2}$ rather than the role of endogenous NFAs.

Although the ability of NFAs to activate PPAR- $y$ at readily achievable plasma concentrations is well established, this may not be their only mechanism of action. NFAs are known to alkylate thiol groups via the Michael reaction [27] and the large majority of plasma NFAs are in fact present as protein adducts [28]. These adducts, however, are primarily to serum albumin or other proteins unlikely to be involved in signaling pathways. Nevertheless, alkylation of signaling proteins might well underlie certain NFA effects. It has been shown that NFAs alkylate the p 65 subunit of NF- $\kappa \mathrm{B}$, thus reducing its DNA-binding activity [16]. This mechanism has been proposed to mediate the protective effect of NFAs on cardiac ischemia/reperfusion injury, although involvement of other mechanisms, including PPAR- $\gamma$ activation, was not ruled out [24]. More recently it has been shown that NFA alkylation of atypical protein kinase $\mathrm{C} \zeta$ inhibits bradykinininduced $\mathrm{Ca}^{++}$influx in pulmonary epithelial cells [29]. Other studies have identified NFA effects not readily related to PPAR- $\gamma$ [30-32], including induced expression of antiinflammatory and cytoprotective genes under control of the heat shock transcription factor [33], but these studies did not identify a specific mechanism for the observed effects. These data suggest that NFA actions involve both PPAR$\gamma$-dependent and -independent mechanisms, although this question requires further investigation.

Failure of $\mathrm{OA}-\mathrm{NO}_{2}$ to upregulate Nrf2 activity under noninflammatory conditions appears unexpected, given the substantial increase in PPAR- $\gamma$ activity we observed. PPAR- $\gamma$ knockdown has been shown to block $\mathrm{O}_{2}$-induced increases in Nrf2 expression [20] while PPAR- $\gamma$ agonists upregulate activity of this antioxidant transcription factor [34]. In the latter system, however, induction was weak in the absence of additional stimulation with retinoic acid, an activating ligand for the RXR receptor with which PPAR- $\gamma$ forms a heterodimer required for transcriptional activity. NFAs have also been reported to upregulate Nrf2 activity and expression by alkylation of the inhibitor protein Keap-1 [3537], which both maintains a cytosolic location for Nrf2 and marks it for ubiquitination and subsequent degradation. Other evidence suggests that NFAs may activate PPAR- $\gamma$ and Nrf2 by distinct post-transcriptional pathways, with the latter involving phosphatidylinositol-3-kinase and protein kinase C [38]. Notably, stimulation of reporter gene activity required NFA concentrations at least 10-fold higher for Nrf2 than for PPAR- $\gamma$. These different potencies may account for our observation that, under noninflammatory conditions, a single $50 \mu \mathrm{g}$ injection of $\mathrm{OA}-\mathrm{NO}_{2}$ upregulated PPAR- $\gamma$ but not Nrf2 activity. In this context, NFA effects on Nrf2 would appear to be an intriguing area for further investigation.

\section{Conclusions}

Our results in a murine model of ALI support the antiinflammatory effects of NFAs that have been demonstrated in vitro and in a limited number of other disease models. They also show, for the first time, that direct pulmonary delivery of an NFA can have beneficial effects in lung disease.
Inflammation is an important feature of many lung diseases, including asthma and chronic obstructive pulmonary disease, and synthetic PPAR- $\gamma$-activating thiazolidinediones have been proposed as treatments for these diseases. As diabetes therapies, however, these agents are known to be associated with adverse effects. Our results suggest that NFAs, and perhaps $\mathrm{OA}-\mathrm{NO}_{2}$ specifically, might be attractive alternatives for these diseases as well as ALI.

\section{Acknowledgment}

This work was supported by NIH Grant HL093196 (to R. C. Reddy).

\section{References}

[1] G. M. Matuschak and A. J. Lechner, "Acute lung injury and the acute respiratory distress syndrome: pathophysiology and treatment," Missouri Medicine, vol. 107, no. 4, pp. 252-258, 2010.

[2] G. Matute-Bello, C. W. Frevert, and T. R. Martin, "Animal models of acute lung injury," American Journal of Physiology, vol. 295, no. 3, pp. L379-L399, 2008.

[3] P. A. Ward, "Oxidative stress: acute and progressive lung injury," Annals of the New York Academy of Sciences, vol. 1203, pp. 53-59, 2010.

[4] K. J. Bosma, R. Taneja, and J. F. Lewis, "Pharmacotherapy for prevention and treatment of acute respiratory distress syndrome: current and experimental approaches," Drugs, vol. 70, no. 10, pp. 1255-1282, 2010.

[5] J. Becker, C. Delayre-Orthez, N. Frossard, and F. Pons, "Regulation of inflammation by PPARs: a future approach to treat lung inflammatory diseases?" Fundamental and Clinical Pharmacology, vol. 20, no. 5, pp. 429-447, 2006.

[6] R. Kostadinova, W. Wahli, and L. Michalik, "PPARs in diseases: control mechanisms of inflammation," Current Medicinal Chemistry, vol. 12, no. 25, pp. 2995-3009, 2005.

[7] L. A. Moraes, L. Piqueras, and D. Bishop-Bailey, "Peroxisome proliferator-activated receptors and inflammation," Pharmacology and Therapeutics, vol. 110, no. 3, pp. 371-385, 2006.

[8] A. Nencioni, S. Wesselborg, and P. Brossart, "Role of peroxisome proliferator-activated receptor $\gamma$ and its ligands in the control of immune responses," Critical Reviews in Immunology, vol. 23, no. 1-2, pp. 1-13, 2003.

[9] T. J. Standiford, V. G. Keshamouni, and R. C. Reddy, "Peroxisome proliferator-activated receptor- $\gamma$ as a regulator of lung inflammation and repair," Proceedings of the American Thoracic Society, vol. 2, no. 3, pp. 226-231, 2005.

[10] K. S. Lee, S. R. Kim, S. J. Park et al., "Peroxisome proliferator activated receptor $\gamma$ modulates reactive oxygen species generation and activation of nuclear factor- $\kappa \mathrm{B}$ and hypoxiainducible factor $1 \alpha$ in allergic airway disease of mice," Journal of Allergy and Clinical Immunology, vol. 118, no. 1, pp. 120127, 2006.

[11] P. R. S. Baker, Y. Lin, F. J. Schopfer et al., "Fatty acid transduction of nitric oxide signaling: multiple nitrated unsaturated fatty acid derivatives exist in human blood and urine and serve as endogenous peroxisome proliferator-activated receptor ligands," The Journal of Biological Chemistry, vol. 280, no. 51, pp. 42464-42475, 2005.

[12] F. J. Schopfer, Y. Lin, P. R. S. Baker et al., "Nitrolinoleic acid: an endogenous peroxisome proliferator-activated receptor $\gamma$ 
ligand," Proceedings of the National Academy of Sciences of the United States of America, vol. 102, no. 7, pp. 2340-2345, 2005.

[13] V. B. O’Donnell, J. P. Eiserich, A. Bloodsworth et al., "Nitration of unsaturated fatty acids by nitric oxide-derived reactive species," Methods in Enzymology, vol. 301, pp. 454-470, 1999.

[14] P. R. S. Baker, F. J. Schopfer, S. Sweeney, and B. A. Freeman, "Red cell membrane and plasma linoleic acid nitration products: synthesis, clinical identification, and quantitation," Proceedings of the National Academy of Sciences of the United States of America, vol. 101, no. 32, pp. 11577-11582, 2004.

[15] B. Coles, A. Bloodsworth, S. R. Clark et al., "Nitrolinoleate inhibits superoxide generation, degranulation, and integrin expression by human neutrophils: novel antiinflammatory properties of nitric oxide-derived reactive species in vascular cells," Circulation Research, vol. 91, no. 5, pp. 375-381, 2002.

[16] T. Cui, F. J. Schopfer, J. Zhang et al., "Nitrated fatty acids: endogenous anti-inflammatory signaling mediators," The Journal of Biological Chemistry, vol. 281, no. 47, pp. 3568635698, 2006.

[17] T. R. Ulich, L. R. Watson, S. M. Yin et al., "The intratracheal administration of endotoxin and cytokines: I. Characterization of LPS-induced IL-1 and TNF mRNA expression and the LPS-, IL-1-, and TNF-induced inflammatory infiltrate," American Journal of Pathology, vol. 138, no. 6, pp. 1485-1496, 1991.

[18] V. R. Narala, M. R. Smith, R. K. Adapala et al., "Curcumin is not a ligand for peroxisome proliferator-activated receptor- $y$," Gene Therapy and Molecular Biology, vol. 13, no. 1, pp. 20-25, 2009.

[19] Y. Li, J. Zhang, F. J. Schopfer et al., "Molecular recognition of nitrated fatty acids by PPAR gamma," Nature Structural \& Molecular Biology, vol. 15, no. 8, pp. 865-867, 2008.

[20] H. Y. Cho, W. Gladwell, X. Wang et al., "Nrf2-regulated PPAR $\gamma$ expression is critical to protection against acute lung injury in mice," American Journal of Respiratory and Critical Care Medicine, vol. 182, no. 2, pp. 170-182, 2010.

[21] R. C. Reddy and T. J. Standiford, "Nrf2 and PPAR $\gamma$ : PPARtnering against oxidant-induced lung injury," American Journal of Respiratory and Critical Care Medicine, vol. 182, no. 2, pp. 134135,2010

[22] R. C. Reddy, "Immunomodulatory role of PPAR-gamma in alveolar macrophages," Journal of Investigative Medicine, vol. 56, no. 2, pp. 522-527, 2008.

[23] S. Borniquel, E. A. Jansson, M. P. Cole, B. A. Freeman, and J. O. Lundberg, "Nitrated oleic acid up-regulates PPAR $\gamma$ and attenuates experimental inflammatory bowel disease," Free Radical Biology and Medicine, vol. 48, no. 4, pp. 499-505, 2010.

[24] V. Rudolph, T. K. Rudolph, F. J. Schopfer et al., "Endogenous generation and protective effects of nitro-fatty acids in a murine model of focal cardiac ischaemia and reperfusion," Cardiovascular Research, vol. 85, no. 1, pp. 155-166, 2010.

[25] H. Liu, Z. Jia, S. Soodvilai et al., "Nitro-oleic acid protects the mouse kidney from ischemia and reperfusion injury," American Journal of Physiology, vol. 295, no. 4, pp. F942-F949, 2008.

[26] D. Tsikas, A. A. Zoerner, A. Mitschke, and F. M. Gutzki, "Nitro-fatty acids occur in human plasma in the picomolar range: a targeted nitro-lipidomics GC-MS/MS study," Lipids, vol. 44, no. 9, pp. 855-865, 2009.

[27] L. M. S. Baker, P. R. S. Baker, F. Golin-Bisello et al., "Nitro-fatty acid reaction with glutathione and cysteine. Kinetic analysis of thiol alkylation by a michael addition reaction," The Journal of Biological Chemistry, vol. 282, no. 42, pp. 31085-31093, 2007.
[28] V. Rudolph, F. J. Schopfer, N. K. Khoo et al., "Nitro-fatty acid metabolome: saturation, desaturation, $\beta$-oxidation, and protein adduction," The Journal of Biological Chemistry, vol. 284, no. 3, pp. 1461-1473, 2009.

[29] C. J. Guo, F. J. Schopfer, L. Gonzales et al., "Atypical PKCzeta transduces electrophilic fatty acid signaling in pulmonary epithelial cells," Nitric Oxide, vol. 25, no. 3, pp. 366-372, 2011.

[30] N. K. Khoo, V. Rudolph, M. P. Cole et al., "Activation of vascular endothelial nitric oxide synthase and heme oxygenase1 expression by electrophilic nitro-fatty acids," Free Radical Biology and Medicine, vol. 48, no. 2, pp. 230-239, 2010.

[31] D. E. Artim, F. Bazely, S. L. Daugherty et al., "Nitro-oleic acid targets transient receptor potential (TRP) channels in capsaicin sensitive afferent nerves of rat urinary bladder," Experimental Neurology, vol. 232, no. 1, pp. 90-99, 2011.

[32] X. Tang, Y. Guo, K. Nakamura et al., "Nitroalkenes induce rat aortic smooth muscle cell apoptosis via activation of caspasedependent pathways," Biochemical and Biophysical Research Communications, vol. 397, no. 2, pp. 239-244, 2010.

[33] E. Kansanen, H. K. Jyrkkänen, O. L. Volger et al., "Nrf2dependent and -independent responses to nitro-fatty acids in human endothelial cells: identification of heat shock response as the major pathway activated by nitro-oleic acid," The Journal of Biological Chemistry, vol. 284, no. 48, pp. 3323333241, 2009.

[34] E. Y. Park, I. J. Cho, and S. G. Kim, "Transactivation of the PPAR-responsive enhancer module in chemopreventive glutathione S-transferase gene by the peroxisome proliferatoractivated receptor- $\gamma$ and retinoid X receptor heterodimer," Cancer Research, vol. 64, no. 10, pp. 3701-3713, 2004.

[35] T. Tsujita, L. Li, H. Nakajima et al., "Nitro-fatty acids and cyclopentenone prostaglandins share strategies to activate the Keap1-Nrf2 system: a study using green fluorescent protein transgenic zebrafish," Genes to Cells, vol. 16, no. 1, pp. 46-57, 2011.

[36] E. Kansanen, G. Bonacci, F. J. Schopfer et al., "Electrophilic nitro-fatty acids activate Nrf2 by a Keap1 cysteine 151independent mechanism," The Journal of Biological Chemistry, vol. 286, no. 16, pp. 14019-14027, 2011.

[37] L. Villacorta, J. Zhang, M. T. Garcia-Barrio et al., "Nitrolinoleic acid inhibits vascular smooth muscle cell proliferation via the Keap1/Nrf2 signaling pathway," American Journal of Physiology, vol. 293, no. 1, pp. H770-H776, 2007.

[38] D. J. Bates, P. K. Smitherman, A. J. Townsend, S. B. King, and C. S. Morrow, "Nitroalkene fatty acids mediate activation of Nrf2/ARE-dependent and PPARgamma-dependent transcription by distinct signaling pathways and with significantly different potencies," Biochemistry, vol. 50, no. 36, pp. 77657773, 2011. 


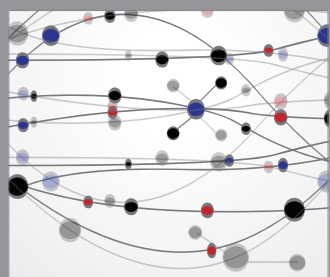

The Scientific World Journal
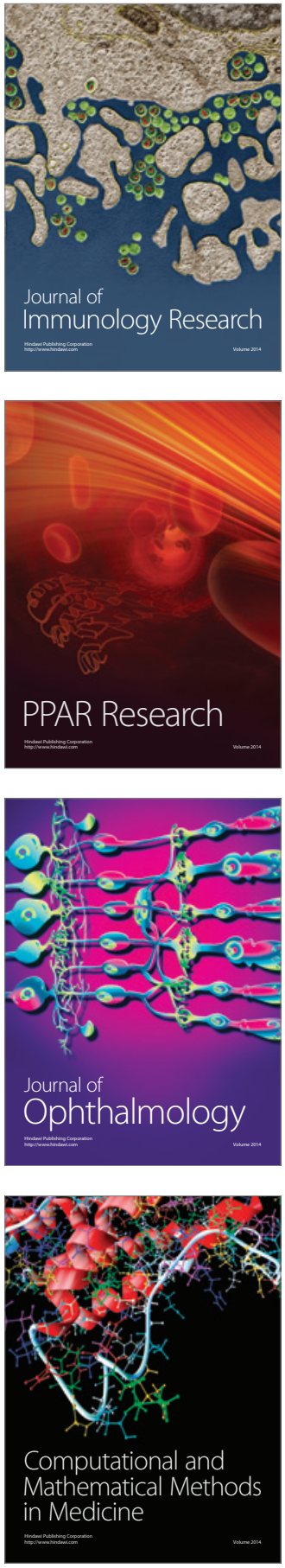

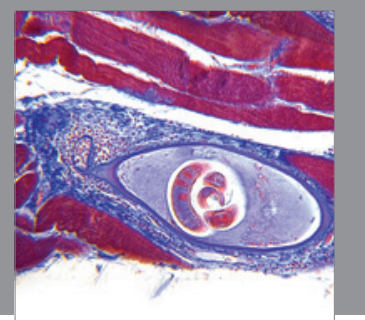

Gastroenterology

Research and Practice
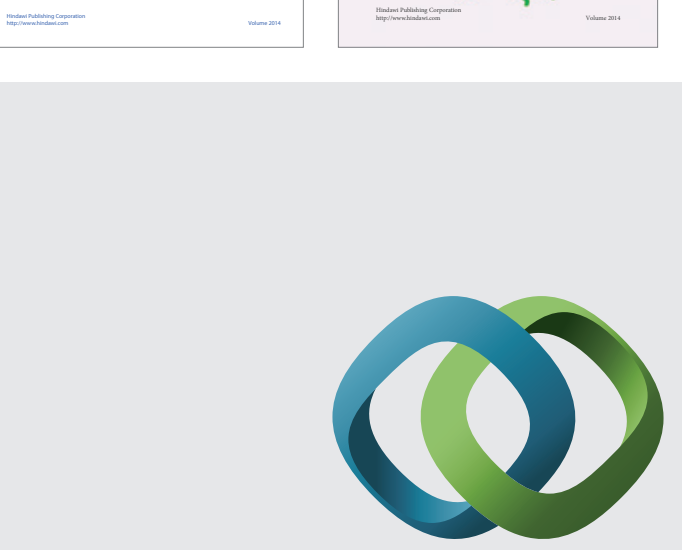

\section{Hindawi}

Submit your manuscripts at

http://www.hindawi.com
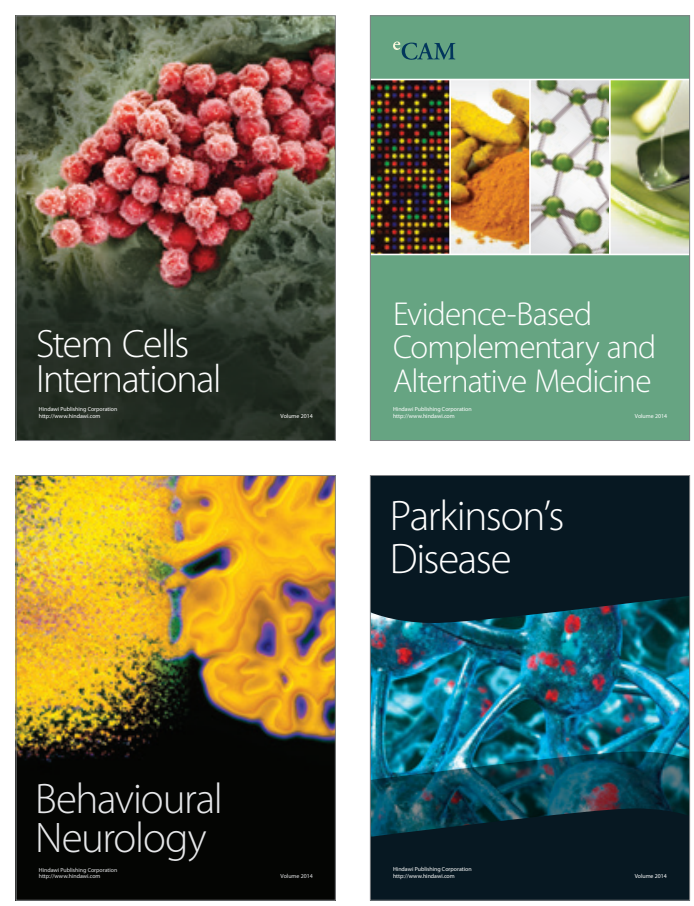

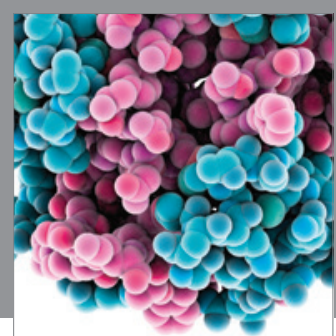

Journal of
Diabetes Research

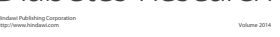

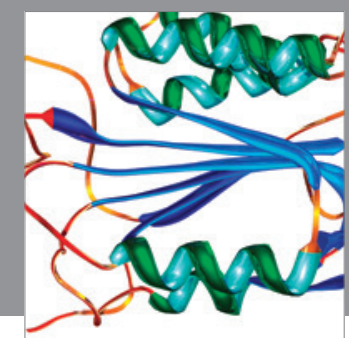

Disease Markers
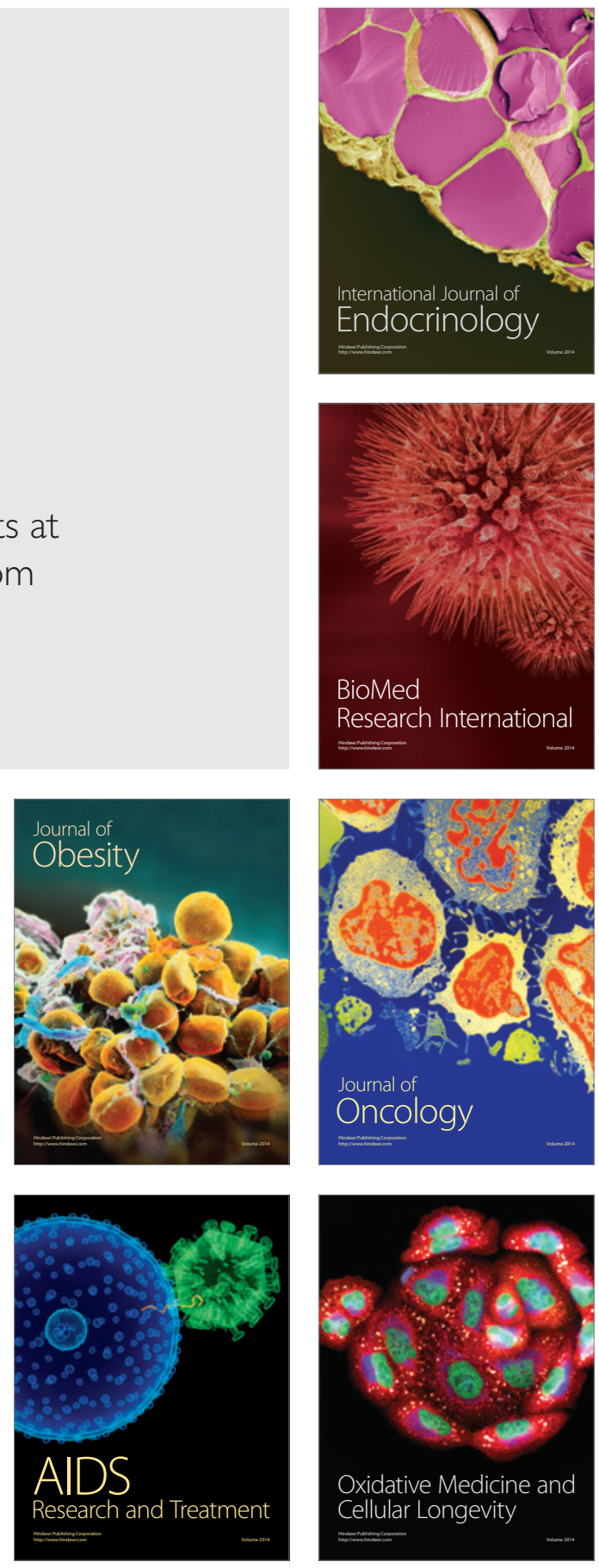